Néstor Shimabukuro Tokashiki ${ }^{(*)}$

y Oscar Alejos Guzmán ${ }^{(*)}$

\title{
La naturaleza de las iniciativas privadas y el control de las decisiones de la Administración Pública $\left.{ }^{(\star \star}\right)^{(* \star *)}$
}

\section{The nature of the private initiatives and the control of the decisions of the Public Administration}

\author{
ES IMPRESCINDIBLE QUE TANTO ADMINISTRADORES COMO ADMINISTRACIÓN PÚBLICA, \\ COMPRENDAN QUE EN LOS ESPACIOS EN DONDE LA DISCRECIONALIDAD ESTÁ HABILITADA, \\ LAS DECISIONES QUE SE TOMEN DEBEN ENCONTRARSE DEBIDAMENTE MOTIVADAS. Y \\ ELLO NO SOLO PORQUE CONSTITUYE UNA EXIGENCIA DEL PRINCIPIO DE INTERDICCIÓN DE \\ LA ARBITRARIEDAD, SINO PORQUE ASÍ SE PERMITE SU CONTROL POR PARTE DEL PODER \\ JUDICIAL, CONTROL QUE SE HABILITA PERMITIENDO LA IMPUGNACIÓN POR PARTE DEL \\ PETICIONANTE DE LA INICIATIVA PRIVADA.
}

\begin{abstract}
Resumen: A pesar de la evolución del régimen de promoción de la inversión privada con relación a los proyectos de inversión bajo la óptica de iniciativas privadas persisten muchos defectos en su regulación, sobre todo en la etapa de evaluación, lo cual genera serios desincentivos para la captación de inversionistas privados. Uno de esos defectos deriva de su consideración como peticiones de gracias y de cómo la Administración entiende este tipo de peticiones. Teniendo dicha problemática en la mira, proponemos una relectura de la naturaleza de las iniciativas privadas que asegure que las decisiones que al respecto tome la Administración Pública sean objeto de un verdadero control de legalidad.
\end{abstract}

Palabras clave: Asociaciones Público Privadas - Iniciativas Privadas Peticiones de Gracia - Discrecionalidad - Motivación

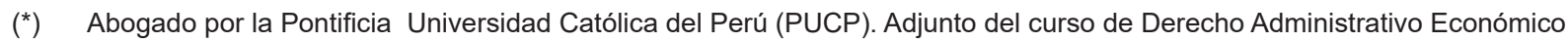
en la Pontificia Universidad Católica del Perú (PUCP) y del curso Seminario de Derecho Administrativo en la Universidad Nacional Mayor de San Marcos (UNMSM). Experto en Derecho Administrativo y Regulatorio. Asociado de CMS-Grau. Correo electrónico: nestor.shimabukuro@cms-grau.com

${ }^{* *}$ Abogado por la Universidad Nacional Mayor de San Marcos (UNMSM). Experto en Derecho Administrativo y Regulatorio. Asociado de CMS-Grau. Correo electrónico: oscar.alejos@cms-grau.com

${ }^{* * *}$ La responsabilidad por lo que se afirme en el presente trabajo pertenece exclusivamente a los autores y no compromete ni adelanta en modo alguno la opinión de la entidad privada para la cual prestan sus servicios profesionales.

${ }^{* * * *}$ ) Nota del Editor: el artículo fue recibido el 1 de junio del 2017 y su publicación fue aprobada el 26 de junio del mismo año. 
La naturaleza de las iniciativas privadas y el control de las decisiones de la Administración Pública The nature of the private initiatives and the control of the decisions of the Public Administration

\begin{abstract}
Despite the evolution of the private investment promotion regime in relation to investment projects under private initiatives, there are many shortcomings in its regulation, especially at the evaluation stage, which creates serious disincentives for attracting private investors. One of these defects derives from its consideration as requests of graces and of how the Administration understands this type of petitions. Having this problem in mind, we propose a rereading of the nature of private initiatives to ensure that decisions taken by the Public Administration in this regard are subject to a true control of legality.
\end{abstract}

Keywords: Public Private Partnerships - Private Initiatives Requests for Grace - Discretionality - Motivation

\section{Introducción}

El Decreto Legislativo 1224, Decreto Legislativo del Marco de Promoción de la Inversión Privada mediante Asociaciones Público Privadas y Proyectos en Activos (En adelante. "Ley de APP") y su respectivo reglamento aprobado por el Decreto Supremo No. 410-2015-EF, pese a las críticas u objeciones legales que se pueden realizar sobre ambas normas, denotan con todo la intención de consolidar y ordenar bajo un solo texto normativo, la promoción de la inversión privada mediante la regulación de los procesos y modalidades para el desarrollo de infraestructura pública, servicios públicos, servicios vinculados a estos, proyectos de investigación aplicada y/o innovación tecnológica y la ejecución de proyectos en activos.

Sin embargo, lo preocupante, contingente y peligroso, para muchos inversionistas e inclusive para el propio Estado, es que se mantiene el desconocimiento generalizado del contenido y alcance de la naturaleza jurídica de las iniciativas privadas como peticiones graciables.

Precisamente, el presente artículo tiene como objetivo determinar una correcta comprensión de la naturaleza jurídica de las iniciativas privadas, partiendo desde una visión netamente teórica de las peticiones graciables, a efectos de determinar su contenido y alcance, lo cual a su vez, nos permitirá comprender las distintas peticiones que generan la emisión de un acto graciable (indultos, pensiones de gracia, solicitud para formular políticas, solicitud para la derogación o modificación de disposiciones legales, entre otras).

\section{Sobre la naturaleza de las iniciativas privadas}

Las iniciativas privadas, tal como han sido concebidas en el marco jurídico de promoción de la inversión privada, tienen el carácter o naturaleza de petición de gracia. De esa manera, el artículo 33.4 del Decreto Legislativo 1224 dispone de manera expresa lo siguiente:

"Artículo 33.- De la naturaleza de las iniciativas privadas

$$
\text { (..) }
$$

33.4 Las iniciativas privadas tienen el carácter de peticiones de gracia a que se refiere el artículo 112 de la Ley 27444 , Ley del Procedimiento Administrativo General, en lo que sea pertinente. En consecuencia, el derecho del proponente se agota con la presentación de la iniciativa privada ante el Organismo Promotor de la Inversión Privada, sin posibilidad de cuestionamiento o impugnación del pronunciamiento en sede administrativa o judicial. Las iniciativas privadas mantienen su carácter de petición de gracia hasta que se convoque el proceso de selección que corresponda, en cuyo caso es de aplicación lo dispuesto en las respectivas bases y/o en la legislación aplicable en lo que sea pertinente; o hasta la suscripción del contrato correspondiente en caso se adjudique directamente por no haber terceros interesados. (...)" (énfasis agregado).

En concordancia con ello, el artículo 112 de la Ley 27444, Ley del Procedimiento Administrativo General (En adelante. "LPAG”), dispone expresamente lo siguiente:

"Artículo 112.- Facultad de formular peticiones de gracia 


\section{Néstor Shimabukuro Tokashiki y Oscar Alejos Guzmán}

112.1 Por la facultad de formular peticiones de gracia, el administrado puede solicitar al titular de la entidad competente la emisión de un acto sujeto a su discrecionalidad o a su libre apreciación, o prestación de un servicio cuando no cuenta con otro título legal específico que permita exigirlo como una petición en interés particular.

112.2 Frente a esta petición, la autoridad comunica al administrado la calidad graciable de lo solicitado y es atendido directamente mediante la prestación efectiva de lo pedido, salvo disposición expresa de la ley que prevea una decisión formal para su aceptación.

112.3 Este derecho se agota con su ejercicio en la vía administrativa, sin perjuicio del ejercicio de otros derechos reconocidos por la Constitución".

Antes de analizar la naturaleza jurídica de las iniciativas privadas, resulta importante e interesante formularnos las siguientes preguntas: ¿Qué entendemos por petición de gracia? ¿Cuáles son los alcances y contenidos de la petición de gracia?

La petición de gracia es una especie del género "derecho de petición" que se encuentra consagrado expresamente en el numeral 20 del artículo 2 de la Constitución, dentro del capítulo "Derechos fundamentales de la persona", que a la letra dispone expresamente lo siguiente:

"Artículo 2.- Derechos fundamentales de la persona

Toda persona tiene derecho:

\section{$(\ldots)$}

20. A formular peticiones, individual o colectivamente, por escrito ante la autoridad competente, la que está obligada a dar al interesado una respuesta también por escrito dentro del plazo legal, bajo responsabilidad.

Los miembros de las Fuerzas Armadas y de la Policía Nacional solo pueden ejercer individualmente el derecho de petición (...)".

Dicha disposición constitucional tiene su concreción y desarrollo legislativo, precisamente, en la LPAG, y en la jurisprudencia del Tribunal Constitucional peruano. De esa manera, podemos apreciar que el artículo 106 de la LPAG establece lo siguiente:

"Artículo 106.- Derecho de petición administrativa

106.1 Cualquier administrado, individual o colectivamente, puede promover por escrito el inicio de un procedimiento administrativo ante todas y cualesquiera de las entidades, ejerciendo el derecho de petición reconocido en el Artículo 2 inciso 20) de la Constitución Política del Estado.

106.2 El derecho de petición administrativa comprende las facultades de presentar solicitudes en interés particular del administrado, de realizar solicitudes en interés general de la colectividad, de contradecir actos administrativos, las facultades de pedir informaciones, de formular consultas y de presentar solicitudes de gracia.

106.3 Este derecho implica la obligación de dar al interesado una respuesta por escrito dentro del plazo legal" (énfasis agregado).

En ese contexto normativo, el Tribunal Constitucional ha definido las notas esenciales del "derecho de petición", determinando su contenido y alcance, como derecho fundamental de toda persona. Así, entre otras sentencias, podemos apreciar la recaída en el Expediente No. 1042-2002-AA/TC que dispone en su fundamento 2.2.4., lo siguiente:

"El contenido esencial de un derecho fundamental está constituido por aquel núcleo mínimo e irreductible que posee todo derecho subjetivo reconocido en la Constitución, que es indisponible para el legislador, debido a que su afectación supondría que el derecho pierda su naturaleza y entidad. En tal sentido, se 


\section{La naturaleza de las iniciativas privadas y el control de las decisiones de la Administración Pública The nature of the private initiatives and the control of the decisions of the Public Administration}

desatiende o desprotege el contenido esencial de un derecho fundamental, cuando este queda sometido a limitaciones que lo hacen impracticable y lo despojan de la protección constitucional otorgada.

En el caso del derecho de petición, su contenido esencial está conformado por dos aspectos que aparecen de su propia naturaleza y de la especial configuración que le ha dado la Constitución al reconocerlo: el primer aspecto es el relacionado estrictamente con la libertad reconocida a cualquier persona para formular pedidos escritos a la autoridad competente; y, el segundo, unido irremediablemente al anterior, está referido a la obligación de la referida autoridad de otorgar una respuesta al peticionante.

Esta respuesta oficial, de conformidad con lo previsto en el inciso 20 del artículo 2 de la Constitución, deberá necesariamente hacerse por escrito y en el plazo que la ley establezca. Asimismo, la autoridad tiene la obligación de realizar todos aquellos actos que sean necesarios para evaluar materialmente el contenido de la petición y expresar el pronunciamiento correspondiente, el mismo que contendrá los motivos por los que se acuerda acceder o no a lo peticionado, debiendo comunicar lo resuelto al interesado o interesados.

Sobre la materia debe insistirse en que es preciso que la contestación oficial sea motivada; por ende, no es admisible jurídicamente la mera puesta en conocimiento al peticionante de la decisión adoptada por el funcionario público correspondiente.

En consecuencia, la acción oficial de no contestar una petición o hacerlo inmotivadamente trae como consecuencia su invalidez por violación, por omisión de un deber jurídico claro e inexcusable (...)" (énfasis agregado).

Resulta importante indicar que la referida sentencia desarrolla además las distintas manifestaciones especiales del derecho de petición contenidas en el numeral 20 del artículo 20 de la Constitución. Asimismo, y tal vez lo más interesante, interpreta los alcances y da contenido a los artículos 112, 107, 108, 110 y 111 de la LPAG. De esa manera, el Tribunal Constitucional desarrolla hasta cinco ámbitos de operatividad del derecho de petición: "a) La petición gracial

Es aquella que se encuentra referida a la obtención de una decisión administrativa a consecuencia de la discrecionalidad y libre apreciación de un ente administrativo.

Esta modalidad es stricto sensu la que originó el establecimiento del derecho de petición, en razón de que la petición no se sustenta en ningún título jurídico específico, sino que se atiene a la esperanza o expectativa de alcanzar una gracia administrativa. A lo sumo, expone como fundamento para la obtención de un beneficio, tratamiento favorable o liberación de un perjuicio no contemplado jurídicamente, la aplicación de la regla de merecimiento.

En ese sentido, la petición prevista en el artículo 112 de la Ley 27444 está destinada a obtener un indulto, alcanzar la formulación de nuevas políticas, la modificación o derogación de disposiciones, la creación o mejoramiento de la infraestructura, el acrecentamiento o modernización de los servicios públicos, la realización de actividades, etcétera.

\section{b) La petición subjetiva}

Es aquella que se encuentra referida a la solicitud individual o colectiva que tiene por objeto el reconocimiento administrativo de un derecho administrativo; es decir, conlleva a la admisión de la existencia de una facultad o atribución para obrar o abstenerse de obrar y para que el administrado peticionante haga exigible a terceros un determinado tipo de prestación o comportamiento.

En ese sentido, la petición prevista en el artículo 107 de la Ley 27444 está destinada a obtener la constitución, declaración, reconocimiento u otorgamiento de un derecho, así como a alcanzar la constatación de un hecho de relevancia administrativa, el ejercicio de una facultad, 


\section{Néstor Shimabukuro Tokashiki y Oscar Alejos Guzmán}

o la formulación de una legítima oposición o contradicción a una decisión administrativa.

Como manifestación jurídica, la petición subjetiva puede pluralmente consumarse en el reconocimiento de una pretensión, en donde el beneficiado podrá en el futuro exigir a terceros el cumplimiento de un deber y obtener del Estado la ejecución de una sanción contra quien lo incumpla; como expresión de señorío se obtiene el albedrío para optar entre la ejecución o no ejecución de una acción; como expresión de un poder privativo se puede crear, modificar o extinguir facultades u obligaciones mediante el ejercicio de la autonomía de la voluntad.

\section{c) La petición cívica}

Es aquella que se encuentra referida a la representación de un grupo indeterminado de personas o de la colectividad en su conjunto, la cual tiene por objeto la protección y promoción del bien común y el interés público.

En ese sentido, la petición prevista en el artículo 108 de la Ley 27444 está destinada a exponer la existencia de problemas generales, trabas u obstáculos normativos o viciosas prácticas administrativas que afectan el acceso ciudadano a las entidades, a su relación con los titulares o funcionarios con capacidad de decisión, etcétera. En puridad, sirven para exponer críticas y formular sugerencias para mejorar la calidad y extensión del servicio administrativo.

d) La petición informativa

Es aquella que se encuentra referida a la obtención de documentación oficial contenida en los bancos informativos o registros manuales de la institución requerida.

En ese sentido, la petición prevista en el artículo 110 de la Ley 27444 está destinada a obtener el suministro de datos estadísticos, dictámenes, resoluciones, etcétera que pudieran obrar en poder de un ente administrativo (...).

e) La petición consultiva

Es aquella que se encuentra referida a la obtención de un asesoramiento oficial en relación con una materia administrativa concreta, puntual y específica.

En ese sentido, la petición prevista en el artículo 111 de la Ley 27444 está destinada a obtener una colaboración instructiva acerca de las funciones y competencias administrativas o sobre los alcances y contenidos de la normatividad o reglamentos técnicos aplicables al peticionante. Con ello se consigue eliminar cualquier resquicio de duda o incertidumbre en torno a la relación administración-administrado".

Del análisis de la sentencia del Tribunal Constitucional, podemos apreciar que no en todos los casos el contenido de las modalidades del derecho de petición será el mismo, puesto que el alcance de la respuesta o de la actividad que la Administración despliegue con relación al mismo, será distinto, dependiendo del título jurídico que el particular invoque para fundamentar su petición.

Con carácter general, en el ordenamiento jurídico español, el derecho de petición se refiere únicamente a la consecución de "actos graciables" y no a la realización de intereses legítimos o derechos subjetivos. En esa línea, la doctrina española nos resulta muy útil para entender el contenido de las peticiones graciables tal como se encuentra regulada en nuestro ordenamiento jurídico.

De esa manera, Colom Pastor define el derecho de petición como:

"el derecho de los ciudadanos de dirigir peticiones a los poderes públicos que señalen las leyes, sobre las materias de su competencia, cuando no son titulares de derechos subjetivos o de intereses legítimos. En efecto, si el ciudadano es titular de un derecho subjetivo o de un interés legítimo, lo que debe dirigir a la Administración es una solicitud de iniciación de un procedimiento o ejercitar el derecho de acción ante los tribunales. Por consiguiente, el ciudadano solo podrá ejercer el derecho de petición en 


\section{La naturaleza de las iniciativas privadas y el control de las decisiones de la Administración Pública The nature of the private initiatives and the control of the decisions of the Public Administration}

las condiciones que ya conocemos cuando no es titular de derechos subjetivos o de intereses legítimos" (Colom Pastor 1997, 39-40).

Es por ello que los actos administrativos que resuelven las peticiones de gracia son inimpugnables o irrecurribles, ya que se parte de la premisa que el derecho de recurrir lo ejercen únicamente los titulares de derechos subjetivos o de intereses legítimos. Esto es precisamente lo que está detrás y le otorga fundamento al artículo 112 de la LPAG y del numeral 33.4 del artículo 33 del Decreto Legislativo 1224.

\section{Caracteres de la petición graciable}

Otro aspecto interesante que se debe tomar en cuenta son los caracteres de la petición graciable. Siguiendo a Colom Pastor, la petición (en nuestro medio interesarse por un acto graciable) es calificada como un acto discrecional y político. Sin embargo, como bien señala dicho autor, el derecho de petición tomando en cuenta los caracteres antes mencionados, hay que analizarlo desde la perspectiva del qué pide y a quién se lo pide. A decir de dicho autor,

"En efecto, para el ciudadano que ejercita el derecho de petición y que por consiguiente no tiene derecho subjetivo ni interés legítimo a que se acceda a lo solicitado, el acto es graciable. En cambio, desde la perspectiva de la Administración, no existe la categoría del acto graciable, ya que la Administración, valorando lo que es más oportuno o más conveniente para el interés público debe otorgar o denegar la petición, por ello el acto es discrecional o, en supuestos excepcionales, político" (Colom Pastor 1997, 43).

En nuestro medio, las notas características del derecho de petición como acto graciable recogen los mismos caracteres desarrollados por la doctrina española.

Para Morón Urbina(1), las peticiones graciables han sido conceptualizadas como aquellas que no pueden apoyarse en otro título alguno que el genérico derecho de petición reconocido en la Constitución e implica una suerte de esperanza o expectativa de que la Autoridad acceda a lo solicitado en atención a las razones sustentadas por el peticionante. En base a ello, las características de la petición graciable poseen las siguientes peculiaridades jurídicas: (i) apoyarse exclusivamente en el derecho genérico de petición consagrado en la Constitución y no en un derecho material que le haga exigible el contenido de lo pedido; y, (ii) la Administración posee discrecionalidad para apreciar el pedido del administrado, en función del interés público que le ha sido encomendado.

En esa misma línea expositiva, para Martin Tirado ${ }^{(2)}$, en base a lo desarrollado por la sentencia del Tribunal Constitucional que hemos venido comentando, la petición graciable está dirigida a la obtención de una decisión dotada de discrecionalidad y de libre apreciación por parte de la autoridad administrativa. Dicho autor, sobre la base del artículo 112 de la LPAG, destaca las notas características de la petición graciable resumidas en los siguientes aspectos: (i) inexistencia de un título específico; (ii) obligación de autoridad administrativa de recibirla y responder en un plazo razonable; (iii) discrecionalidad administrativa; y, (iv) agotamiento en su ejercicio.

En ese sentido, siguiendo a González Pérez ${ }^{(3)}$, el titular de un derecho subjetivo está legitimado para hacerlo valer en un procedimiento: (i) cuando el derecho subjetivo dimana de la norma jurídica, al darse los supuesto de hecho que determinan su nacimiento, la persona en

(1) Cónfer Juan Carlos Morón Urbina, "La generación por Iniciativa Privada de Proyectos Públicos: La nueva colaboración público - Privada y el interés público," Derecho \& Sociedad 24 (2005): 281.

(2) Cónfer Richard Martin Tirado, "El control judicial de las peticiones de gracia: El indulto y las iniciativas privadas," Gaceta Constitucional 31 (junio 2010): 184-8.

(3) Cónfer Jesús González Pérez, Sistema Jurídico de las Administraciones Públicas (Pamplona: Thomson Reuters - Civitas, 2009), 58. 


\section{Néstor Shimabukuro Tokashiki y Oscar Alejos Guzmán}

quien concurran está legitimada para incoar el procedimiento cuyo objeto es el reconocimiento del derecho; (ii) cuando el procedimiento tiene por objetivo remover el obstáculo que se oponía al ejercicio de un derecho civil, ostentará la legitimación el titular del derecho privado; y, (iii) cuando el titular de un derecho subjetivo administrativo preexistente, en un procedimiento cuya finalidad sea el hacer efectivas las consecuencias que se deriven de aquel derecho.

Por su parte, para García de Enterría y Fernández Rodríguez ${ }^{(4)}$, el derecho subjetivo se concreta en pretensiones activas frente a la Administración en orden a la consecución de prestaciones patrimoniales correlativas a otras tantas obligaciones de esta, cualquiera que sea su origen, contractual, extracontractual, o legal, pretensiones de respeto a titularidades jurídico - reales, pretensiones resultantes de situaciones jurídicas favorables creadas por un acto de este carácter dictado por la propia Administración, y de obligado cumplimiento para ella y, finalmente, las pretensiones de respeto a las situaciones de libertad individual formalmente definidas como tales.

De otro lado, muy ligado a la titularidad y al ejercicio del derecho subjetivo(5), se sostiene que el proponente de iniciativas privadas no tiene calidad de interesado o titular de algún interés legítimo para incoar e intervenir en un procedimiento administrativo antes de la emisión del respectivo acto administrativo.

Bajo dichos caracteres debemos entender que cuando al administrado (personas naturales, jurídicas o inversionistas) le interesa un acto graciable, como es el caso de presentar proyectos recaídos bajo el régimen de iniciativas privadas, no aparece configurado en el ámbito constitucional ni administrativo como titular de un derecho prestacional, ya que el peticionante no es en realidad titular de un derecho subjetivo o interés legítimo.

En ese sentido, puesto que la presentación de iniciativas privadas se refiere a facultades graciables, la concesión o no de lo pedido quedará a la discrecionalidad del destinatario de la petición. Ello tiene sentido si consideramos que el titular o proponente de la iniciativa privada lo que busca en realidad es que el proyecto sea declarado de interés público, lo que será determinado por la Administración u Organismo Promotor de la Inversión Privada (En adelante "OPIP"), de acuerdo con los caracteres propios del proyecto y siguiendo los lineamientos establecidos en el marco normativo correspondiente.

De otro lado, es importante notar que a pesar que se trata de una petición graciable, la autoridad competente se encuentra en la obligación de recibir el proyecto, darle trámite y responder en un plazo razonable de acuerdo con el marco normativo correspondiente. Ello en doctrina ha sido catalogado como "obligaciones positivas" del derecho de petición. En esa línea, siguiendo a Colom Pastor ${ }^{(6)}$, el poder público queda realmente sometido a una serie de obligaciones positivas, entre las que destaca la de recibir la petición, consecuencia directa y elemental del derecho a dirigir peticiones a los poderes públicos, admitir en su caso y tramitar la petición, esto es, realizar un examen material de la pretensión y la obligación de resolver la petición en un plazo razonable, motivándola y comunicando la resolución.

En nuestro medio, Martin Tirado señala válidamente que, "esta condición de resolver lo solicitado por el administrado dentro de un plazo razonable, constituye simplemente una protección al núcleo irreductible o contenido esencial del derecho de petición. Por ende, sería correcto afirmar que si se vulnera esta característica principal, se estaría vulnerando en sí el derecho de petición del administrado" (Martín 2010, 186).

De la misma manera, el Tribunal Constitucional, en la sentencia bajo comentario, afirma

(4) Cónfer Eduardo García de Enterría y Tomás - Ramón Fernández Rodríguez, Curso de Derecho Administrativo, 14ª ed. Tom. II (Pamplona: Thomson Reuters - Civitas, 2015), 485.

(5) Cónfer González Pérez, Sistema Jurídico de las Administraciones Públicas, 58-9.

(6) Cónfer Bartolomeu Colom Pastor, El derecho de petición (Madrid: Marcial Pons, 1997), 74. 


\section{La naturaleza de las iniciativas privadas y el control de las decisiones de la Administración Pública The nature of the private initiatives and the control of the decisions of the Public Administration}

válidamente que el derecho de petición implica un cúmulo de obligaciones u mandatos para la Administración. Entre ellos, podemos mencionar los siguientes: (i) facilitar los medios para que el ciudadano pueda ejercitar el derecho de petición sin trabas absurdas o innecesarias; (ii) abstenerse de cualquier forma o modo de sanción al peticionante, por el solo hecho de haber ejercido dicho derecho; (iii) admitir y tramitar el petitorio; (iv) resolver en el plazo señalado por la ley de la materia la petición planteada, ofreciendo la correspondiente fundamentación de la determinación; y, (v) comunicar al peticionante la decisión adoptada.

Otro aspecto que caracteriza la petición graciable es el alto contenido discrecional y político en la consecución de la declaratoria de interés. Desde una acepción amplia del concepto de discrecionalidad ${ }^{(7)}$, esta hace alusión a un determinado modo de operar, de actuar, de realizar algo, consistente en la adopción de decisiones, mediante una elección entre diferentes alternativas.

El maestro Cassagne ${ }^{(8)}$ precisa el fenómeno de la discrecionalidad, en la libertad que le permite actuar a la Administración eligiendo entre "actuar y no actuar" (discrecionalidad de actuación), mientras que en otros supuestos se configura como una libertad de opción que le permite elegir la solución entre varias alternativas igualmente justas (discrecionalidad de elección). En este último supuesto, siguiendo a dicho autor, no puede suponerse que la facultad de elección se otorga siempre al órgano administrativo dentro de un margen de apreciación dejado por el ordenamiento a elección del mismo, toda vez que hay numerosos ejemplos en los que la facultad de elegir se encuentra limitada a escoger una solución entre dos o más que se encuentran regladas. De esa manera, puede existir libertad de elección (discrecionalidad) sin que haya margen de apreciación, porque el legislador ya lo acotó con una decisión predeterminada.

Asimismo, la discrecionalidad en la libertad de actuar y elegir no debería contener argumentos extrajurídicos. Como bien advierte y enseña Cassagne ${ }^{(9)}$, aunque la discrecionalidad se apoye sobre la base de elementos extrajurídicos, elementos técnicos o de valores políticos, el núcleo de la discrecionalidad se encuentra en el modo o manera de elegir y siempre será jurídico, en el sentido que no puede ser irrazonable o arbitrario, por tanto, siempre estará sujeta a la ley y al derecho, y consecuentemente, al control jurisdiccional.

Ello es de suma importancia para entender el fenómeno de la discrecionalidad y el núcleo fuerte que compone y caracteriza las peticiones graciables: campear en el límite de la arbitrariedad. Nos explicamos. Como bien advertimos sobre la referencia a Colom Pastor ${ }^{(10)}$, desde la perspectiva de la Administración, las peticiones (interés en un acto graciable) dirigidas a la misma, en el ejercicio del derecho de petición, dan lugar a actos discrecionales o actos políticos y éstos son, en cierto modo, un tipo de actividad discrecional, lo que obliga siempre a la emisión de resoluciones motivadas.

Precisamente, el deslinde entre lo discrecional y arbitrario parte de la idea de la fundamentación o motivación. De esa manera, a decir de Fernández Rodríguez, "en su significación más primaria el principio en cuestión postula una distinción entre arbitrariedad y discrecionalidad, entre lo que es fruto de la mera voluntad o el puro capricho de los administradores y lo que por el contrario, cuenta con el respaldo -mayor o menor, mejor o peor, es otra cuestiónde una fundamentación que lo sostiene" (2008, 81).

(7) Cónfer Eva Desdentado Garoca, Discrecionalidad Administrativa y planeamiento urbanístico. Construcción teórica y análisis jurisprudencial (Navarra: Aranzadi, 1999), 70-1.

(8) Cónfer Juan Carlos Cassagne, El principio de legalidad y el control judicial de la discrecionalidad administrativa, $1^{\text {a }}$ ed. (Buenos Aires: Marcial Pons, 2009), 192-3.

(9) Cónfer Cassagne, El principio de legalidad y el control judicial de la discrecionalidad administrativa, 192-3.

(10) Cónfer Colom Pastor, El derecho de petición, 84. 
Néstor Shimabukuro Tokashiki y Oscar Alejos Guzmán

En ese sentido, como bien señala Colom Pastor,

“(...) lo más característico del derecho de petición en el momento actual es su vertiente defensiva o de garantía jurídica para proteger los intereses jurídicos no protegidos por el derecho. Esto significa que los poderes públicos están obligados a estimar las peticiones con derechos y a contestar motivadamente las peticiones formuladas en el ejercicio del derecho de petición y desde esta perspectiva estamos ante una técnica de cierre del Estado social y democrático de Derecho" (Colom Pastor1997, 93).

En relación con el agotamiento de su ejercicio, en vista que el proponente de la iniciativa privada o el interesado de un acto graciable no es titular de un derecho subjetivo, como hemos desarrollado líneas atrás, el derecho de petición se agota o culmina al presentarse el proyecto o la solicitud ante la Administración.

Sin embargo, ello no es absoluto, ya que debe primar la garantía de los derechos fundamentales de la persona, como es el debido proceso en el ámbito administrativo.

En síntesis, puede apreciarse claramente que las distintas especies o variables del derecho de petición (como es el caso de las peticiones graciables en el Perú, tales como las iniciativas privadas e indultos, entre otras) se reconducen al derecho fundamental que le asiste a toda persona (natural o jurídica) en la libertad de formular y presentar pedidos, solicitudes, o escritos a la autoridad competente reconocido en la Constitución; y, recibir una respuesta debidamente fundamentada o motivada por parte de esta, previa evaluación de su contenido, que determinará finalmente el acceso o no a lo peticionado, tal como bien dispone el artículo 106 de la LPAG.

Es importante enfatizar que el derecho de petición no puede concebirse y construirse únicamente a partir de la regulación legislativa de este derecho (por ejemplo, LPAG y Decreto Legislativo 1224), sino de la propia Constitución, tal como hemos venido reiterando a lo largo del presente artículo, como bien lo ha desarrollado Fernández Sarasola(11).
Asimismo, compartimos las formulaciones de González Pérez quien afirma que la naturaleza jurídica del derecho de petición es un derecho de carácter constitucional y, por tanto, fundamental de la persona, que va más allá del proceso y del procedimiento administrativo (González Pérez 1961, 17).

Debe quedar claro además que no se trata aquí de dos derechos distintos ni mucho menos contrapuestos: "derecho de petición" por un lado y "derecho de petición de gracia" o "derecho de formular peticiones graciable" por otro, sino se trata precisamente de una variable del género - especie, respectivamente.

Con todo, para un correcto entendimiento de la naturaleza jurídica o carácter de las iniciativas privadas como petición de graciable establecida en el numeral 33.4 del artículo 34 del Decreto Legislativo 1224, debe leerse y entenderse conjuntamente con lo dispuesto en el inciso 20 del artículo 2 de la Constitución y en el artículo 106 de la LPAG, aunado a la jurisprudencia del Tribunal Constitucional que, como fuente del derecho, juega un rol fundamental en la interpretación y armonización del ordenamiento jurídico. Una lectura y comprensión aislada y distinta prescindiendo de los preceptos legales antes señalados, constituye reducir al máximo el contenido esencial del derecho fundamental de petición reconocido en la Constitución.

\section{La petición (graciable) como "derecho fundamental de contenido formal”}

Tal como hemos apuntado en los acápites anteriores, si bien el administrado o toda

(11) Véase Ignacio Fernández Sarasola, "Un derecho residual: el derecho de petición en el ordenamiento constitucional español," Revista Vasca de Administración Pública 58 (Setiembre - Diciembre 2000). 


\section{La naturaleza de las iniciativas privadas y el control de las decisiones de la Administración Pública The nature of the private initiatives and the control of the decisions of the Public Administration}

persona que le interesa la emisión de un acto graciable, no es titular de un derecho a la concesión de lo pedido, es decir, su ejercicio "no comprende el derecho a obtener una respuesta favorable a lo solicitado", tiene derecho a los aspectos formales del procedimiento administrativo de petición graciable. Esto es precisamente, lo que la doctrina española, apoyada con las sentencias de su Tribunal Constitucional, ha catalogado como un "derecho fundamental de contenido formal"(12).

Como bien señala Colom Pastor ${ }^{(13)}$, el peticionante, muy aparte de tener derecho a obtener una respuesta debidamente motivada, tiene derecho a que el contenido de la resolución se ajuste a los principios generales del derecho, a que la resolución no infrinja o conculque o vulnere el principio de igualdad o de la interdicción de la arbitrariedad de los poderes públicos. Pese a que el peticionante interesado en un acto graciable no ostenta la titularidad de un derecho subjetivo o interés legítimo al logro de lo pedido, sí tiene un interés protegido por el derecho, como el derecho a la igualdad o a que no se le trate de manera arbitraria, de esa manera, como bien afirma dicho autor el peticionante "es titular de un interés protegido de forma refleja por el derecho".

En efecto, debemos enfatizar que las peticiones graciables siguen la suerte de un procedimiento administrativo (reglado o no), y, por tanto, les resultan aplicables los principios jurídicos del propio procedimiento y la norma constitucional en relación al debido proceso.

Estos principios son en realidad, un conjunto de "normas básicas" que inspiran el procedimiento administrativo, siendo que la propia LPAG en el numeral 2 del Artículo IV de su Título Preliminar, señala que "servirán también de criterio interpretativo para resolver las cuestiones que puedan suscitarse en la aplicación de las reglas de procedimiento, como parámetros para la generación de otras disposiciones administrativas de carácter general, y para suplir los vacíos en el ordenamiento administrativo"(14).

De esa manera, al procedimiento administrativo de evaluación de iniciativas privadas les resultan totalmente aplicables los principios jurídicos contenidos en la LPAG, así como los principios generales del derecho y los preceptos constitucionales. Desconocer la aplicación de dichos preceptos es reducir al máximo las garantías jurídicas que todo administrado ostenta en defensa de sus intereses.

Como bien expone Huapaya Tapia, "precisamente la lógica de la LPAG está en consonancia con la doctrina dominante actual del Derecho Administrativo, y por tal motivo ha establecido una regulación del procedimiento administrativo eminentemente garantista, y que asegura la existencia de una tutela administrativa efectiva al ciudadano en el inicio, la ordenación, la instrucción y el término del procedimiento, e inclusive en la eventual fase impugnatoria del mismo, así como en la ejecución de las decisiones administrativas" (2013, 122).

En ese sentido, son de recibo y de aplicación directa, entre otras garantías, las establecidas en el numeral 2 del Artículo IV del Título Preliminar de la LPAG, en la evaluación de iniciativas privadas: debido procedimiento,

(12) Cónfer Colom Pastor, El derecho de petición, 84-7. De la misma manera, cónfer Juan Carlos Morón Urbina, "Las concesiones de infraestructura a iniciativa de inversionistas," IUS ET VERITAS 35 (2007): 156-80. Del mismo autor, "Los derechos del iniciador de proyectos de infraestructura. Las lecciones por aprender de la STC No. 01387-2009-PA/TC," en autores varios, Modernizando el Estado para un país mejor. Ponencias del IV Congreso Nacional de Derecho Administrativo, Palestra/ Asociación Peruana de Derecho Administrativo, Lima, 2010, 69-88.

(13) Cónfer Colom Pastor, El derecho de petición, 87-8.

(14) Para una mayor profundidad sobre el tema, véase los trabajos, entre otros, de Francisco López Menudo, "Los principios generales del procedimiento administrativo." Revista de Administración Pública 129 (Septiembre-diciembre 1992): 19-76. Disponible en: www.cepc.es; y, Guido Santiago Tawil, "El principio de colaboración en el procedimiento administrativo," en Procedimiento Administrativo. Publicación de los integrantes de la Cátedra de Derecho Administrativo de la UBA a cargo del Dr. Guido Santiago Tawil, dir. Guido Santiago Tawil (Buenos Aires: Abeledo Perrot, 2009), 159-163. 


\section{Néstor Shimabukuro Tokashiki y Oscar Alejos Guzmán}

impulso de oficio, imparcialidad, informalismo, celeridad, eficacia, participación, simplicidad, predictibilidad.

Sin perjuicio de ello, debemos poner mayor énfasis en el principio del debido proceso en el ámbito administrativo, que como bien mencionamos anteriormente tiene una connotación constitucional. Siguiendo a Huapaya Tapia ${ }^{(15)}$, el debido proceso en el ámbito administrativo refleja la garantía constitucional del derecho de defensa. A la fecha, con las modificaciones introducidas por el Decreto Legislativo 1272 a la LPAG, y siguiendo los parámetros de la jurisprudencia del Tribunal Constitucional, se ha ampliado el listado de derechos derivados de la garantía constitucional del debido proceso al ámbito administrativo.

Precisamente, como bien ha desarrollado Morón Urbina(16), en las reflexiones que se pueden destacar de la sentencia del Tribunal Constitucional recaído en el Expediente No. 1387-2009-PA/TC (caso "DHMONT") (17), el derecho subjetivo del iniciador o proponente de las iniciativas privadas es asegurársele un debido procedimiento administrativo en las fases de admisibilidad, exposición, adjudicación, negociación y firma del contrato, es decir, en las actuaciones correspondientes a la fases de (i) planeamiento y programación; (ii) formulación; (iii) estructuración; y, (iv) transacción, tal como lo establece el Decreto Legislativo 1224.

A decir de dicho autor,

"En una perspectiva constitucional, esta compatibilidad no resulta difícil teniendo en cuenta que el debido procedimiento se define como la regulación jurídica que de manera previa limita a la administración y comprende diversas medidas de protección/garantías a favor de los administrados, de modo que las actuaciones en curso de un procedimiento concreto no dependan de su arbitrariedad, sino que se encuentren disciplinadas por la normatividad respetando la dignidad de la persona y otros derechos fundamentales vinculados. Dicha regla resulta aplicable tanto en procedimientos e los que se encausen petitorios administrativos que cuenten con algún derecho subjetivo de base (por ejemplo, petición de licencias o pensiones) como en peticiones de gracias (por ejemplo, iniciativas privadas)".

Por tal motivo, compartimos con Morón Urbina ${ }^{(18)}$ las conclusiones en base al caso Dhmont, en la medida que el Tribunal Constitucional dejó sentado lo siguiente: i) (re confirmar) el respeto por el debido procedimiento en garantía de los derechos fundamentales de los ciudadanos como deber de la Administración y ii) pese a que el marco jurídico correspondiente determina expresamente que el derecho del proponente se agota con la presentación de la iniciativa privada ante el OPIP, sin posibilidad de cuestionamiento o impugnación del pronunciamiento en sede administrativa o judicial, abre la posibilidad de impugnar, de manera muy excepcional, a través de la vía de amparo, los pronunciamientos o decisiones que se emitan siempre que se vulnere algún derecho fundamental.

\section{Reflexiones en relación al control de las decisiones de la Administración Pública respecto de las iniciativas privadas}

De lo expuesto hasta aquí, el lector habrá reconocido un aspecto muy preocupante del

(15) Cónfer Ramón Huapaya Tapia, “¿Cuáles son los alcances del Derecho al "debido procedimiento administrativo” en la Ley del Procedimiento Administrativo General?," en Administración Pública, Derecho Administrativo y Regulación. Estudios y cuestiones. Segunda edición actualizada y ampliada (Lima: Ara Editores, 2013), 128-48.

(16) Cónfer Morón Urbina, "Los derechos del iniciador de proyectos de infraestructura. Las lecciones por aprender de la STC No. 011387-2009-PA/TC," 81-8.

(17) Para visualizar la sentencia puede recurrir al siguiente enlace: http://www.tc.gob.pe/jurisprudencia/2009/01387-2009-AA.html

(18) Cónfer Morón Urbina, "Los derechos del iniciador de proyectos de infraestructura. Las lecciones por aprender de la STC No. 011387-2009-PA/TC," 81-8. 


\section{La naturaleza de las iniciativas privadas y el control de las decisiones de la Administración Pública The nature of the private initiatives and the control of the decisions of the Public Administration}

régimen actual de las iniciativas privadas, consistente en la limitación de cuestionar en sede administrativa o judicial los pronunciamientos del OPIP en la fase de evaluación de las iniciativas privadas hasta la suscripción del respectivo contrato, tomando en cuenta el carácter que ostentan como petición graciable. Dicho ello, es imperativo plantearse las siguientes cuestiones: ¿Son las iniciativas privadas peticiones de gracia en todos sus extremos?, ¿cuál es realmente el alcance de considerar a las iniciativas privadas como peticiones de gracia? Vamos por partes.

En relación a la primera cuestión, consideramos que a la fecha y dada la profusa regulación existente, no podemos seguir pensando que las iniciativas privadas son peticiones de gracia en todos sus extremos. Dos argumentos fundamentales abonan a este obligado y necesario cambio de criterio: (i) la estructuración por etapas del procedimiento de evaluación de las iniciativas privadas; y, (ii) el carácter reglado que dichas etapas presenta.

El primer argumento lo hemos precisado líneas arriba cuando hablamos de las distintas fases de evaluación. Por su parte, respecto del segundo argumento, no puede negarse que desde su solicitud, el procedimiento para admitir y, posteriormente, evaluar las iniciativas privadas se encuentra ampliamente reglado, es decir, no solo se establecen los requisitos que deben cumplir, sino además se regulan plazos para el administrado y la Administración.

Prueba fehaciente del carácter reglado es la reciente modificación del Reglamento del Decreto Legislativo 1224 realizada mediante Decreto Supremo No. 068-2017-EF. En efecto, conforme al nuevo texto del artículo 33 del reglamento, para la admisión a trámite de las iniciativas privadas, la Administración no solo se encuentra sujeta a un plazo para resolver y notificar, sino además está sujeta al silencio administrativo positivo. Es decir, ante su silencio, la ley presume una respuesta afirmativa a favor del peticionante.

Lo dicho demuestra que, por lo menos el extremo de la admisión de las iniciativas privadas, no puede sujetarse al régimen de las peticiones de gracia, en la medida que se encuentra completamente regulada.

Vale destacar que esta lectura no requiere de una interpretación creativa del marco legal vigente. En efecto, si miramos con atención el artículo 33 del Decreto Legislativo 1224, apreciaremos que el numeral 4 dispone textualmente lo siguiente: "las iniciativas privadas tienen el carácter de peticiones de gracia a que se refiere el artículo 112 de la Ley 27444, Ley del Procedimiento Administrativo General, en lo que sea pertinente". Si la misma norma indica que las iniciativas privadas tiene carácter de petición de gracia "en lo que sea pertinente", necesariamente debe entenderse que existe extremos respecto de los cuales "no es pertinente" aplicar el régimen de petición de gracia.

Esta misma línea argumentativa ya fue defendida entre nosotros por Morón Urbina quien ha sostenido que, en base a las reflexiones que ha dejado el caso Dhmont, la restricción debe entenderse circunscrita a la imposibilidad de cuestionar las razones por las cuales llevaron a la OPIP a declarar de interés o no la iniciativa privada evaluada. En cambio, los aspectos que son reglados, procedimentales o formales, como son los actos emitidos en el marco de la evaluación y calificación de las iniciativas privadas en las distintas fases que la componen, sí serán recurribles en sede administrativa o judicial.

Ello ha sido puesto en manifiesto por la doctrina, en la medida que si bien el administrado o toda persona no tienen derecho al logro o consecución de lo pedido, tiene derecho a los aspectos procedimentales del derecho de petición, esto es, a una resolución fundada, dictada siguiendo un procedimiento. En este extremo, Colom Pastor ha señalado que precisamente, "estos elementos reglados pueden ser controlados por los tribunales, que pueden anular las decisiones adoptadas por los poderes públicos contestando a una petición si se infringen estos límites" $(1997,86)$.

Lamentablemente, esa no ha sido la interpretación del carácter graciable del régimen de iniciativas privadas por parte del OPIP correspondiente. 


\section{Néstor Shimabukuro Tokashiki y Oscar Alejos Guzmán}

En efecto, para el caso concreto de presentación de proyectos recaídos bajo el régimen de iniciativas privadas sobre proyectos de Asociaciones Público - Privadas autofinanciadas y cofinanciadas (en todos los niveles de gobierno) para el desarrollo de infraestructura pública, servicios públicos, servicios vinculados a estos, proyectos de investigación aplicada y/o innovación tecnológica, proyectos en activos y demás regulados en el Decreto Legislativo 674, el OPIP correspondiente, así como las entidades públicas que intervienen, entienden que su evaluación y calificación hasta llegar a la declaratoria de interés está sujeto a una libre apreciación o a un alto nivel de discrecionalidad, pero ajustándose estrictamente a los lineamientos establecidos en el marco jurídico correspondiente que lo regula (Decreto Legislativo 1224 y su norma reglamentaria aprobado por el Decreto Supremo No. 410-2015-EF y su respectiva modificatoria).

Sin embargo, consideramos que dicha apreciación es incorrecta si partimos de la tesis que en determinados extremos no cabe aplicar el régimen de peticiones de gracia a las iniciativas privadas.

Sobre la base de ello, no cabe dudar que el peticionante tiene derecho a cuestionar todos los aspectos formales y procedimentales relacionados con la evaluación de la consistencia de la iniciativa privada con las prioridades nacionales, regionales o locales, según corresponda, la evaluación preliminar de viabilidad técnica de la iniciativa privada, la elaboración del informe de evaluación, la introducción de ampliaciones y/o modificaciones que considere convenientes y/o necesarias en el contenido y diseño de la iniciativa privada, la evaluación del Ministerio de Economía y Finanzas sobre los montos que estén dispuestos a comprometer el Estado y el sustento de capacidad presupuestal para desarrollar las iniciativas privadas y cómo las entidades aplican dicha información para emitir su respectiva opinión dependiendo de la fase o etapa en que se encuentre el proyecto.

En línea con lo anterior y considerando que los aspectos señalados se encuentran reglados (ahora con mayor intensidad), no podemos dejar de mencionar que la posibilidad de impugnar implica a su vez la posibilidad de corregir errores de la Administración que no deben perjudicar al administrado. Ejemplos de estos errores en la tramitación de las iniciativas privadas hay muchos, desde la elaboración errónea o incompleta del informe de evaluación, o el cálculo incorrecto de los recursos públicos que está dispuesto a comprometer en relación a los aspectos económicos financieros del proyecto, o la solicitud de opinión técnica a una entidad pública que realmente no es competente para evaluar el proyecto, entre otros supuestos.

En otra línea de casos se encuentran los rechazos inmotivados de las iniciativas privadas por inacción de la misma Administración, como sucede cuando los Ministerios, Gobiernos Regionales o Locales no se pronuncian a tiempo respecto de la relevancia de la iniciativa privada.

En todos estos casos, no solo no tiene sentido recurrir a la naturaleza graciable de la iniciativa privada, sino que es ilegal hacerlo. En efecto, estando frente a extremos reglados, no cabe aplicar al régimen de peticiones de gracia, mucho menos para vulnerar el derecho del peticionante a un pronunciamiento expreso y motivado de parte de la Administración.

Incluso si consideramos que en dichos extremos se debe aplicarse el régimen de peticiones de gracia, existen argumentos contundentes para defender la posibilidad de impugnación. En el caso particular de los rechazos por inactividad de la Administración, la doctrina ${ }^{(19)}$ considera que estamos frente a una terminación anormal del procedimiento administrativo que otorga al proponente el derecho a cuestionar la medida adoptada.

Ahora bien, respecto de la segunda cuestión planteada al inicio del presente apartado, es necesario comprende qué significa que las iniciativas privadas sean consideradas peticiones de gracia (en lo que resulte pertinente). Conforme hemos detallado en los apartados anteriores, reconocer su naturaleza como peticiones de gracia implica únicamente reconocer discrecionalidad en la decisión que

(19) Véase Colom Pastor, El derecho de petición, 134-6. 


\section{La naturaleza de las iniciativas privadas y el control de las decisiones de la Administración Pública The nature of the private initiatives and the control of the decisions of the Public Administration}

tome la Administración. Precisamente, en el caso concreto, implica reconocer discrecionalidad a la Administración al momento de decidir si la iniciativa privada es de interés público.

Sin embargo, ello no quiere decir que dicha decisión no esté sujeta a control. Dicho de otro modo, la restricción a la impugnación solo se debe plantear respecto del extremo en el cual la autoridad tiene discrecionalidad ${ }^{(20)}$, es decir, respecto de qué es lo que la Administración considera como conforme al interés público. Sin embargo, conforme ha afirmado la doctrina mayoritaria, ello de ningún modo implica que dicha decisión pueda producirse sin motivación o de forma irracional, como parecen entender algunos funcionarios públicos.

En ese sentido, aun cuando se reconozca que las iniciativas privadas, en determinados extremos del procedimiento al que dan origen, constituyen peticiones de gracia, ello no implica que estén exentas de control. Ergo, el peticionante siempre podrá cuestionar administrativa y judicialmente las decisiones de la Administración que se encuentren desmotivadas o aquellas que contengan una motivación defectuosa.

$Y$ es que en este extremo existe un desconocimiento de lo que debe entenderse por discrecional. Al respecto, vale empezar señalando que discrecional no es lo opuesto a reglado, como bien señaló García de Enterría hace más de medio siglo:

“(...) en todo acto discrecional hay elementos reglados suficientes como para no justificarse de ninguna manera una abdicación total del control sobre los mismos. Estos elementos reglados son, por de pronto, la misma existencia de la potestad, de cuyo ejercicio dimana el acto, la extensión concreta de esta potestad, que es imposible que sea totalmente indeterminada, $y$, en fin, la competencia para ejercitarla.

(...) el fin de las potestades discrecionales es también un elemento reglado de las mismas. En efecto, las autoridades administrativas pueden contar y cuenta, con toda normalidad, con poderes discrecionales, pero no para el cumplimiento de cualquier finalidad, sino precisamente de la finalidad considerada por la Ley, y en todo de la finalidad pública, de la utilidad o interés general" (García de Enterria 1962, 167-8).

Siendo ello así, siempre existe un espacio para el control de las potestades discrecionales, no siendo una excepción en el caso de la evaluación de peticiones de gracia como son las iniciativas privadas. En ese sentido, cabe recordar lo que la doctrina y la jurisprudencia han precisado como límites o criterios de control de las potestades discrecionales.

Especial mención merece Tomás Ramón Fernández, quien ha estudiado ampliamente el tema, con un énfasis necesario en la distinción entre discrecionalidad y arbitrariedad. A criterio de este autor, el cual compartimos, la motivación del acto marca la diferencia entre la discrecionalidad (permitida por nuestro ordenamiento jurídico) y la arbitrariedad (vedada en razón del principio de interdicción de la arbitrariedad):

"La motivación de la decisión comienza, pues, por marcar la diferencia entre lo discrecional y lo arbitrario, y ello, porque si no hay motivación que la sostenga, el único apoyo de la decisión será la sola voluntad de quien la adopta, apoyo insuficiente, como es obvio, en un Estado de Derecho en el que no hay margen, por principio, para el poder puramente personal" $(2008,81)^{(21)}$.

(20) Sobre el concepto de discrecionalidad, así como su diferenciación con figuras afines, cónfer Víctor Baca Oneto, "La discrecionalidad administrativa y la jurisprudencia del Tribunal Constitucional peruano," Revista de Derecho Administrativo 11 (2012): 181-202.

(21) A similar conclusión arriba Rodríguez-Arana al señalar que "la motivación es el correlato, la otra cara de la moneda de la discrecionalidad. Si la discrecionalidad no se motiva, entramos en el proceloso mundo de la arbitrariedad". Jaime RodríguezArana, "Discrecionalidad y motivación del acto administrativo en la Ley española de procedimiento administrativo," Derecho PUCP 67 (2011): 215. 


\section{Néstor Shimabukuro Tokashiki y Oscar Alejos Guzmán}

De la cita se desprende el primer criterio que permite juzgar un acto discrecional para distinguirlo de un acto arbitrario: la motivación. Un segundo criterio -en la teoría de Tomás Ramón Fernández- consiste en que la decisión discrecional contenga una justificación objetiva. Es decir, no basta que el acto se encuentre motivado, sino que dicha motivación debe ser racional.

En palabras del autor citado: "dada una motivación, una razón de la elección, la que sea, esa razón debe ser plausible, congruente con los hechos de los que necesariamente ha de partirse, sostenible en la realidad de las cosas y (...) susceptible de ser comprendida por los ciudadanos, aunque no sea compartida por todos ellos" $(2008,154)$.

Esta posición es compartida por nuestra propia jurisprudencia constitucional. Así, en la sentencia recaída en el Expediente No. 90-2004-AA-TC (Caso Callegari), el Tribunal Constitucional estableció lo siguiente:

“(...) en la discrecionalidad de grado intermedio y menor, el órgano jurisdiccional tiene como cuestión crucial la motivación -elemento inherente al debido proceso, que desarrollemos más adelante-, de la que depende esencialmente la legitimidad de ejercicio de todo poder, y es, por ello, inexcusable e irrenunciable, tal como lo prueba la categórica prohibición constitucional de todo uso arbitrario de aquel. Asimismo, dada una motivación, es decir, una razón de la elección, esta debe ser plausible, congruente con los hechos, en los que necesariamente ha de sustentarse, sostenible en la realidad de las cosas y susceptible de ser comprendida por los ciudadanos, aunque no sea compartida por todos ellos. No basta, como es obvio, cualquier explicación que la Administración convenga en dar en el momento de la obligada rendición de cuentas; estas han de ser, en todo caso, debidamente justificadas.

\section{(...)}

Es por ello que la prescripción de que los actos discrecionales de la Administración del Estado sean arbitrarios exige que estos sean motivados; es decir, que se basen necesariamente en razones y no se constituyan en la mera expresión de la voluntad del órgano que los dicte.

Dichas razones no deben ser contrarias a la realidad y, en consecuencia, no pueden contradecir los hechos relevantes de la decisión. Más aún, entre ellas y la decisión necesariamente debe existir consistencia lógica y coherencia".

Como podrá notarse, el consenso es evidente. Sin embargo, aun así es necesario fundamentar la posición. ¿Por qué las decisiones discrecionales deben motivarse adecuadamente? Además de constituir un requisito de validez de todo acto administrativo, conforme a la Ley del Procedimiento Administrativo General, dos razones fundamentales permiten argumentar que en el caso específico de los actos discrecionales, estos deben encontrarse adecuadamente motivados.

La primera, señalada anteriormente, responde a la necesidad de deslindar lo discrecional $y$, por ende permitido, de lo arbitrario que se encuentra prohibido. La segunda razón -siguiendo el planteamiento de Cassagne ${ }^{(22)}$. se encuentra en la necesidad de garantizar la tutela judicial efectiva y específicamente la garantía de defensa, dado que solo frente a un acto adecuadamente motivado se permite al administrado cuestionar la decisión de la Administración.

Lo expuesto no puede desconocerse respecto del régimen de las iniciativas privadas. Como hemos visto, la ley reconoce aplicable la normativa sobre peticiones de gracia, lo que implica que su declaración de interés constituye una potestad discrecional de la Administración. Sin embargo, ello no implica reconocer una arbitrariedad.

(22) Así en Juan Carlos Cassagne, El principio de legalidad y el control judicial de la discrecionalidad administrativa, $2^{a}$ ed. (Montevideo-Buenos Aires: Editorial B de F, 2016), 276. 
La naturaleza de las iniciativas privadas y el control de las decisiones de

la Administración Pública

The nature of the private initiatives and the control of the decisions of

the Public Administration

Por el contrario, siendo una potestad discrecional, la Administración debe poner mayor énfasis en su evaluación y, por ende, en las razones (motivos) de su decisión discrecional. En razón de ello, resulta insuficiente el simple rechazo o negativa de las iniciativas privadas. Peor aún, resulta sumamente peligroso, ilegal y hasta inconstitucional el rechazo de las iniciativas privadas sin motivación alguna y mediante actos que "notifican" al peticionante que dicha decisión es irrecurrible.

Este modus operandi que se ha vuelto común en nuestro medio no solo no está habilitado por la ley, sino que además es contrario a la noción misma de discrecionalidad que tanto la doctrina como la jurisprudencia se han encargado de delimitar, asegurando que no sea un campo de arbitrariedad en manos de la Administración. En efecto, la exigencia de motivación adecuada sobre la cual se ha hecho tanto énfasis implica necesariamente permitir que el administrado cuestione las decisiones discrecionales que no contengan motivación o cuya motivación no se encuentre racionalmente estructurada.

\section{Conclusiones}

Consideramos que es hora de una renovación en la comprensión de las iniciativas privadas.

En primer lugar, es necesario reconocer que en su tramitación existen espacios reglados en donde no cabe reconocer potestad discrecional alguna.

Pese a que se reconozca que las iniciativas privadas constituyen peticiones de gracia, ello no implica que estén exentas de control alguno, máxime si en determinados extremos del procedimiento son reglados.
En segundo lugar y más importante, es imprescindible que tanto administradores como Administración Pública, comprendan que en los espacios en donde la discrecionalidad está habilitada, las decisiones que se tomen deben encontrarse debidamente motivadas. Y ello no solo porque constituye una exigencia del principio de interdicción de la arbitrariedad, sino porque así se permite su control por parte del Poder Judicial, control que se habilita permitiendo la impugnación por parte del peticionante de la iniciativa privada.

De esa manera, el peticionante siempre podrá cuestionar administrativa y judicialmente las decisiones de la Administración que se encuentren desmotivadas o aquellas que contengan una motivación defectuosa.

\section{Referencias bibliográficas}

Colom Pastor, Bartolomeu. 1997. El derecho de petición. Madrid: Marcial Pons.

Fernández Rodríguez, Tomás Ramón. 2008. De la Arbitrariedad de la Administración. $5^{\mathrm{a}}$ ed. Pamplona: Thomson Civitas

García de Enterría, Eduardo. 1962. La lucha contra las inmunidades del poder en el Derecho Administrativo (poderes discrecionales, poderes de gobierno, poderes normativos). Revista de Administración Pública 38.

González Pérez, Jesús. 1961. Régimen jurídico del derecho de petición. Documentación Administrativa 40 (abril): 17-27.

Huapaya Tapia, Ramón Alberto. 2013. ¿Cuáles son los alcances del Derecho al "debido procedimiento administrativo" en la Ley del Procedimiento Administrativo General? En Administración Pública, Derecho Administrativo y Regulación. Estudios y cuestiones. Segunda edición actualizada y ampliada. Lima: Ara Editores.

Martin Tirado, Richard. 2010. El control judicial de las peticiones de gracia: El indulto y las iniciativas privadas. Gaceta Constitucional 31 (junio): 181-200. 